\title{
The characterisation of pollution aerosol in a changing photochemical environment
}

\author{
M. J. Cubison ${ }^{1,}$, M. R. Alfarra ${ }^{1,}{ }^{* *}$, J. Allan ${ }^{1}$, K. N. Bower ${ }^{1}$, H. Coe ${ }^{1}$, G. B. McFiggans ${ }^{1}$, J. D. Whitehead ${ }^{1}$, \\ P. I. Williams ${ }^{1}$, Q. Zhang ${ }^{2}$, J. L. Jimenez ${ }^{2}$, J. Hopkins ${ }^{3}$, and J. Lee ${ }^{3}$ \\ ${ }^{1}$ School of Earth, Atmospheric and Environmental Science, University of Manchester, Manchester, UK \\ ${ }^{2}$ Dept. of Chemistry and Biochemistry and Cooperative Institute for Research in Environmental Sciences (CIRES), \\ University of Colorado, Boulder, CO, USA \\ ${ }^{3}$ Dept. of Chemistry, University of York, Heslington, York, UK \\ * now at: Cooperative Institute for Research in the Environmental Sciences, University of Colorado, Boulder, CO, USA \\ ** now at: Laboratory for Atmospheric Chemistry, Paul Scherrer Institute, Villigen, Switzerland
}

Received: 11 July 2005 - Published in Atmos. Chem. Phys. Discuss.: 18 October 2005

Revised: 15 August 2006 - Accepted: 21 October 2006 - Published: 13 December 2006

\begin{abstract}
Measurements are presented from a sampling location $50 \mathrm{~km}$ downwind of Greater London, UK, to investigate the timescales required for the atmospheric transformations of aerosol in urban emissions plumes in the context of photochemical age based on the benzene to toluene ratio. It is shown that particles at or around $100 \mathrm{~nm}$ in diameter exhibit the greatest systematic variability in chemical properties, and thus hygroscopic properties, on a timescale of 12 days. The smaller Aitken mode and larger accumulation mode particles exhibit less variability on these timescales, which we propose is as a result of their different residence times in the atmosphere. The larger accumulation particles have been in the atmosphere longer than the $100 \mathrm{~nm}$ particles and their chemistry and hygroscopic properties have been integrated over several days and potentially over several source regions. In contrast, the smaller Aitken mode particles show little systematic variability with photochemical age because their atmospheric lifetimes are short, thus chemical changes and hence changes in water affinity have not had time to occur. Increases in the particle diameter of up to $40 \%$ are observed at $90 \%$ relative humidity in the accumulation mode from the uptake of water as the particles become increasingly soluble in nature.
\end{abstract}

\section{Introduction}

Understanding the nature and transformations of chemical and physical properties of atmospheric aerosol is important to quantify the effect of aerosol on human health and climate change. Epidemiological studies have shown that an

Correspondence to: M. J. Cubison

(michael.cubison@colorado.edu) increase in the mass concentration of atmospheric particulate matter (PM), usually measured with diameter cut-offs of either 2.5 or $10 \mu \mathrm{m}$ diameter $\left(\mathrm{PM}_{2.5}\right.$ and $\left.\mathrm{PM}_{10}\right)$, from average background levels leads to an increase in premature mortality and morbidity in the case of both short- and longterm exposure (e.g. Pope et al., 1992; Wilson and Spengler, 1996; Schwartz et al., 1996; Pope, 2000). The particle chemical composition (Horak et al., 2001; Neuberger et al., 2004; Ghio and Devlin, 2001), surface area (Neuberger et al., 2002; Moshammer and Neuberger, 2003; Zimmer, 2002), number concentration (Penttinen et al., 2001; Donaldson et al., 1998; Sydbom et al., 2001) and diameter (Kim and Jaques, 2000) have all been linked with adverse health effects.

The impact of aerosols remains the largest uncertainty in the radiative forcing of climate (IPCC, 2001). The size increase of aerosol particles resulting from uptake of water vapour has important implications for both the aerosol direct and indirect effects. In their 2001 report, the IPCC proposed that the aerosol size distribution, change in size with relative humidity and solubility were the most important parameters to be studied in understanding of the impact of aerosol on the atmospheric radiation budget.

In the ambient atmosphere, the actual observed physical and chemical properties of aerosol vary greatly between locations and times (see e.g. van Dingenen et al., 2004; Putaud et al., 2004; O'Dowd et al., 2004; Reddy and Boucher, 2004). Separation of the contribution to the aerosol distribution from fresh emissions and the background distribution has been frequently observed in studies of the hygroscopic properties of aerosol using the Hygroscopic Tandem DMA instrument (Rader and McMurry, 1986). Such studies usually report the hygroscopicity of particles as the ratio of their mobility diameter at an elevated relative humidity, $\mathrm{RH}$, to their dry

Published by Copernicus GmbH on behalf of the European Geosciences Union. 
diameter, known as the hygroscopic growth factor, $g(\mathrm{RH})$; typically the elevated relative humidity is $90 \%, \mathrm{~g}_{90}$. Many previous studies have shown an omnipresent background distribution of soluble particles of varying hygroscopicity with $\mathrm{g}_{90} \sim 1.4-1.8$, generally referred to as the more-hygroscopic mode, which is observed in environments as diverse as urban areas (McMurry and Stolzenburg, 1989; Svenningsson et al., 1992; Zhang et al., 1993; Trakumas et al., 1995; McMurry et al., 1996; Vakeva et al., 2002; Cocker et al., 2001), continental background sites (Zhang et al., 1993; Svenningsson et al., 1994; Swietlicki et al., 1999; Väkevä et al., 2002; Zhou et al., 2002) and marine locations (Covert and Heintzenberg, 1993; Berg et al., 1998; Swietlicki et al., 1998, 2000; Maßling et al., 2003). McMurry et al. (1996) showed that in urban areas, a less-hygroscopic mode comprised of carbonaceous chain agglomerates (plus any volatile organic compounds that may have evaporated in the transmission electron microscope beam) was externally mixed with the commonly observed more-hygroscopic mode, which consisted of spherical soluble particles containing a large inorganic component. The attribution of the less-hygroscopic mode to freshly emitted particles has been made by a number of other urban studies (e.g. Swietlicki et al., 1999; Vakeva et al., 2002; Cocker et al., 2001).

The properties of the organic particulates from urban emissions (e.g. traffic) can be altered through physical and chemical processes in the atmosphere. Dilution, condensation and coagulation all have potential to influence the aerosol properties in the urban plume as it is advected away from the source region. Chemical processing of the material in the particulate phase may add significantly to the particle mass if reactive or catalysed uptake of volatile material occurs (e.g. Claeys et al., 2004; Limbeck et al., 2003). Even if significant addition of particle mass does not occur through this route, particle phase chemical processes may make the particles more accessible to subsequent condensation of material from the gas phase, for example by changing the associated water on the particle. Many previous modeling studies have attempted to understand the effects of these different processes on the aerosol distribution (see e.g. Pich et al., 1970; Lee, 1983; Barrett and Clement, 1988; Kulmala et al., 1989; Williams, 1995; Jacobson, 1999; Park and Lee, 2000; Park et al., 2001; Kulmala, 2003; Kulmala et al., 2004a). Some studies estimate that the transfer of organic carbon from hydrophobic to hygroscopic occurrs in the order of 2-3 days (Reddy and Boucher, 2004; Cooke et al., 2002), and in general, the residence time of black carbon and organic matter in the atmosphere is a function of its hygroscopicity (Cooke et al., 2002), indicating that the hygroscopicity of particles in the atmosphere depends on the chemical nature of the organic aerosol component. However, there is increasing evidence that the solubility of particles in the atmosphere is really controlled by the ratio of inorganic to organic material. McFiggans et al. (2005) report predictions of the hygroscopic growth factor, g, given by a newly developed multi-component ther- modynamic hygroscopicity framework, the Aerosol Diameter Dependent Equilibrium Model (ADDEM) (Topping et al., 2005a, b). Contributions to $\mathrm{g}_{90}$ from organic components are shown to be less than 1.1, in comparison to the measured growth of 1.7 from sulphate/nitrate. Atmospheric observations of $g_{90}>1.1$ for the less-hygroscopic mode therefore imply that even these particles exhibit a hygroscopicity that even an oxidised organic component cannot achieve. McFiggans et al. (2005) conclude that, so far as water affinity in the subsaturated regime is concerned, an atmospherically realistic amount of oxidised organic material will only make a minor contribution to water content.

Regardless of the controlling processes, understanding the time scales of transformations of atmospheric aerosol is important for modeling climate change and assessing regional air quality. More soluble particles have a greater impact on the global radiation budget than hydrophobic particles by increasing the aerosol direct effect through their increased size under humid conditions. More-hygroscopic particles also make more efficient cloud condensation nuclei (Weingartner et al., 1997) thus the ageing of particles also influences the aerosol indirect effect.

This work uses an experimental approach to investigate the timescales of the transformations of urban aerosol plumes using an extensive suite of aerosol- and gas-phase instrumentation at an urban background site.

\section{Methods}

An advanced suite of aerosol instrumentation was deployed as part of a large, two-part experimental campaign during the summer of 2003 and spring of 2004. The first Tropospheric Organic Chemistry (TORCH) experiment was located $50 \mathrm{~km}$ north-east of London, UK, with continuous measurements made throughout August 2003, and will form the data set discussed in this study. This location was chosen to sample the pollution plume advected from London by the prevailing southwesterly wind with an air mass age of between 2 to $24 \mathrm{~h}$, in order to study the photochemical processing of the gas and aerosol-phase components of the ambient air.

The TORCH 1 sampling site was located at Writtle Agricultural College, near Chelmsford, Essex, UK, $50 \mathrm{~km}$ northeast of London and therefore downwind of the London emissions plume under prevailing wind conditions. Between the edge of the London urban area and the sampling site the terrain is largely flat, arable land free from major pollution sources. The site was chosen such that the local region was free from local pollution sources for a large variation in the local wind vector, with only the easterly sector influenced by a significant local emissions profile. The site could therefore sample a representative pollution plume advected from the London area without influence from local emissions.

Sampling of meteorological, gas- and aerosol-phase measurements was conducted from the top of a $10 \mathrm{~m}$ high tower 
constructed on site. Access to the tower was restricted to avoid interference with the measurements. Local meteorology was determined by Vaisala humidity and temperature probes, and a R.M. Young sonic anemometer measured the 3 -D wind field at $20 \mathrm{~Hz}$. In addition, a back trajectory analysis of the origins of the air masses arriving at the site was carried out at 12-hourly intervals, depicting the path taken by the air mass reaching the sampling site over the previous five days. The back trajectories were run using the on-line HYSPLIT model developed by the National Oceanic and Atmospheric Administration (NOAA) together with wind field archive data from the European Centre for Medium Range Weather Forecasts (ECMWF). The destination location was $500 \mathrm{~m}$ vertically above the TORCH 1 sampling site at Writtle College, with points along the trajectory determined every $2 \mathrm{~h}$.

A comprehensive suite of instruments from several universities was employed to monitor a large number of gas phase components during the TORCH campaign. Species measured included Ozone (with a TECO TEI49C UV ozone analyser), NO (using a TECO TEI42 trace level chemiluminescence analyser to measure NO), the latter includes a Mo catalyst to convert $\mathrm{NO}_{2}$ to $\mathrm{NO}$ to a derive a measure of $\mathrm{NO}_{\mathrm{x}}$, but thermally unstable oxidized nitrogen species such as PAN may also be converted. A vast array of volatile organic carbon (VOC) measurements were made using 1-D and 2-D Gas-Chromatography Mass-Spectrometry (GC-MS and GCxGC-MS) (Lewis et al., 1996, 2000; Lee et al., 2001; Hopkins et al., 2003). Measurements from these and other instruments shall form the basis of forthcoming published work and shall not be presented in detail here.

Measurement of aerosol from the top of a $10 \mathrm{~m}$ sampling tower poses significant difficulties, owing to effects such as Brownian coagulation and diffusion losses to the wall (Alonso et al., 1999; Malet et al., 2000). To minimise these effects, a specifically designed sampling stack drew aerosol down a $30 \mathrm{~cm}$ diameter plastic tube to laboratory level, where they were iso-kinetically sub-sampled into an $8 \mathrm{~cm}$ diameter stainless steel tube leading to the laboratory. The separate instruments further sub-sampled in an identical iso-kinetic fashion through their own respective sample lines. In this work, the flow rate in the main stack gave a Reynolds number of $10^{3}$, such that diffusional losses for sub-micron particles were minimal above $5 \mathrm{~nm}$ diameter. The steel sub-sampling tube minimises electro-diffusive losses of charged aerosol, and helps to maintain the tube walls at the same temperature as the air flow to avoid wall condensation and possible condensational growth of the aerosol (Barrett and Baldwin, 2001, 2000). Through these considerations, errors arising from aerosol losses are minimised, and an identical aerosol distribution is delivered to each instrument.

The aerosol number size distribution was measured from $3 \mathrm{~nm}$ to $32 \mu \mathrm{m}$ by a Differential Mobility Particle Sizer (DMPS) (Williams et al., 2000), which uses two parallel Differential Mobility Analysers (DMA) coupled to Condensa- tional Particle Counters (CPC, TSI Models 3010 and 3025A) to classify and count the particles according to their size, and an Optical Particle Counter (OPC, Grimm model 1.109). The DMPS instrument was operational from the beginning of the campaign through to 16 August, with the exception of a problem with one of the CPCs on the 7 August and the power cut on the 11th. After 16 August only size information for particle diameters greater than $30 \mathrm{~nm}$ is available due to a problem with the CPC used to measure the ultrafine particles. The OPC was operational from 2 August through to the end of the campaign, except for a power cut on the 11 August.

The aerosol composition was measured using the on-line Aerodyne Aerosol Mass Spectrometer (AMS) (Jayne et al., 2000), which measured size-resolved mass spectra in the range $30 \mathrm{~nm}$ to 1 micron. The AMS uses an aerodynamic lens to focus the particles into a narrow beam, a roughened cartridge heater to vapourise them under high vacuum, and electron-impact ionization followed by a quadrupole mass spectrometer to analyse the vapourised molecules. Particle size is measured via particle time-of-flight. The AMS is operated in two modes: (1) a continuous mass spectrum mode without size information; and (2) a size distribution measurement mode for selected $\mathrm{m} / \mathrm{z}$ settings of the quadrupole. More detailed descriptions of the AMS instrument are available in Jayne et al. (2000); Jimenez et al. (2003); Drewnick et al. (2004), and a detailed description of the analysis technique, including separation of the data from the fresh emissions and background modes, is given by Allan et al. (2003a, 2004b). The sizing measurement of the AMS is described in detail by DeCarlo et al. (2004)

Data coverage from the AMS was complete at 10-min resolution from 30 July to 6 August inclusive, whereafter resolution was decreased to $2 \mathrm{~h}$ due to experiments being carried out investigating the performance of the instrument. A large gap in data coverage exists on 11 to 14 August inclusive due to the power cut and subsequent operational difficulties. A measurement of total particle number concentration in the range $3 \mathrm{~nm}$ to 1 micron was made in parallel to the AMS measurements using a CPC.

The hygroscopicity of the particle population was measured at dry particle diameters of 27, 40,60, 89, 137, 217 and $360 \mathrm{~nm}$ using a HTDMA (Cubison et al., 2005). The hygroscopic growth factor determined at $90 \%$ relative humidity $(\mathrm{RH}), \mathrm{g}_{90}$, was measured at these dry diameters at an hourly resolution. In addition, plots of $\mathrm{g}(\mathrm{RH})$ vs. $\mathrm{RH}$, known as humidograms, determined the hydration and dehydration properties of the aerosol, over a large range of $\mathrm{RH}$, at one or two different dry sizes for each qualitative change in sampled air mass.

Gaps in the time-series data set arise from determination of humidograms, incorrect RH values (usually owing to temperature fluctuations in the laboratory) and power failures on site. During the period from 13 to 19 August only the $89 \mathrm{~nm}$ dry size was measured due to a failed DMA voltage supply. 


\subsection{Elimination of local influences}

Given the aim of this study to investigate the atmospheric transformations of aerosol transported from a source region outside the local area, it is necessary, before analysis, to eliminate from the data set those periods under the influence of local sources. It is required that the measurements represent an advected air mass, and are not dominated by local emissions or processes such as in situ cloud scavenging, which can significantly alter the aerosol population during overnight periods of fog. The technique employed here uses a set of boolean arrays, or flags, the application of each of which removes all the data at those points in time which do not meet the conditions specific to that array. Flags were set up (but not necessarily applied) to eliminate data in the following circumstances: (1) when the measured value of NOx deviated by more than $20 \%$ from the 10 min average data. This was used to remove data under the influence of local sources, e.g. passing vehicles; (2) when the local wind vector implied the sampling location was directly downwind of the site generator (easterly sector); (3) when the local wind speed was less than $1.5 \mathrm{~m} \mathrm{~s}^{-1}$. This was used to eliminate periods when local sources may have been influencing the sampling site; (4) when the local wind vector was not in the $\mathrm{SW}$ quarter. This is useful for considering those measurements which had been advected from London; (5) during the night - eliminated all data from sunset to sunrise; and (6) when the air was deemed to be stratified, and therefore the sampling location was not under the influence of advected air, but in a locally-influenced air layer. Quantification of the stratification of the air mass was achieved by using the Monin-Obukhov length, $L$, which describes the ratio of the horizontal wind vector to the vertical heat flux (Monin and Obukhov, 1954). At night, the vertical heat flux often tends to zero, generating highly stratified layers in the atmosphere near the ground. This reduces advection and hence the sampling stack is dominated by local sources emitting into the stratified layer closest to ground level.

In all cases, the local source flags, that is 1) $\mathrm{NO}_{\mathrm{x}}, 2$ ) generator, 3) wind speed and 6) Monin-Obukhov length were applied when analysing the data. The night-time flag was applied for all the data analysis procedures, principally because at night, the $\mathrm{NO}_{3}$ radical dominates the chemistry of the troposphere, leading to the production of $\mathrm{N}_{2} \mathrm{O}_{5}$, which is rapidly converted to nitric acid in the aqueous phase in the presence of water vapour. Scavenging processes such as these dominate over photochemical transformations occuring during advection in periods of fog. Night-time data was thus not considered directly relevant to the study objectives of this work and excluded from analysis.

\section{Photochemical age of air masses}

Changes in observed aerosol properties are examined as a function of photochemical age of the sampled air mass using two different methods. It is noted that the photochemical age of an air mass is different from the actual transport time required to advect an air mass from a source region to the sampling site, which may, for example, occur during darkness and therefore have little impact from photochemical reactions. Firstly, we consider distinct time periods within the TORCH 1 project time frame for which the air masses sampled have both different source regions and exposure to differing degrees of photochemical transformation. Secondly, we present the changes in the observed properties as a function of age through classification of the photochemical lifetime of the air mass using VOC ratios. Analysis of the VOC profiles in different air masses allows investigation into the timescales over which aerosol age.

The use of VOC ratios in making estimates of the photochemical age of an air mass has been reported in the literature for some time (Calvert, 1976; Roberts et al., 1984; McKeen et al., 1996; Parrish et al., 1992; McKeen and Liu, 1993; Rudolph and Czuba, 2000; Kleinmann et al., 2003). The principle is straightforward although in practice it is difficult to apply, as it requires detailed knowledge of oxidant levels along the air mass trajectory which is seldom available.

At the point of emission, VOCs have characteristic concentration ratios depending on the type of emission source (Kleinmann et al., 2003). Downwind of this source, concentration ratios change as the more reactive compounds are preferentially removed by oxidation. Reaction loss depends on photochemical age, defined here as the time integrated exposure to the $\mathrm{OH}$ radical. This is a simplified case; it would be necessary to include losses from reactions with $\mathrm{O}_{3}$ and $\mathrm{NO}_{3}$ if the products of their reaction rate constants and concentrations were competitive with the $\mathrm{OH}$ ones.

In the ideal case, VOCs are emitted into clean air from a single point emission source of a known ratio, reaction is only with the $\mathrm{OH}$ radical, no diffusion occurs during transport so there is a unique, well-defined travel time, and background air has a negligible VOC concentration (Rudolph and Johnen, 1990). In this case, with negligible dilution, the concentrations of a VOC species $i$ can be described as:

$C_{i}(t)=C_{i}(0) e^{-k i[\mathrm{OH}] t}$.

Dilution in the atmosphere will tend to decrease the concentration of both VOCs, but this is difficult to model so here it is assumed that both species maintain the same footprint and dilute at the same rate, therefore allowing it to be neglected for the purposes of calculating the ratio of their concentrations. Hence, if we know the starting ratio of two VOC species, $i$ and $j$, given by $R_{0}=C_{i}(0) / C_{j}(0)$, by using an estimate of $\mathrm{OH}$ concentration and kinetic rate constants from the literature, it is possible to estimate the photochemical age 


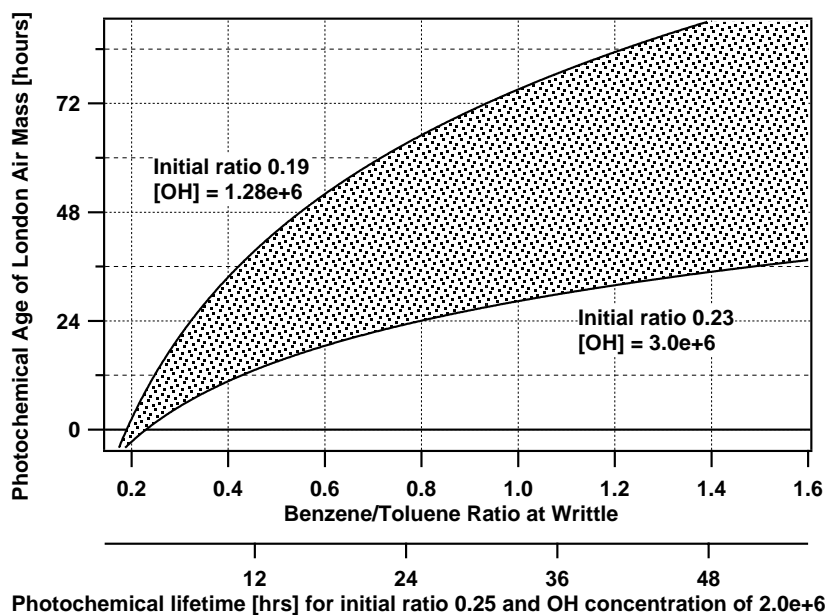

Fig. 1. Graphical representation of the range of estimated photochemical lifetimes of air masses at the TORCH field site based on VOC ratio.

of the air mass, $t_{p h}$, based on the measured VOC ratio

$\begin{aligned} R t & =C_{i}(t) / C_{j}(t): \\ t_{p h} & =\ln \left(R_{t} / R_{0}\right) /\left(k_{j}-k_{i}\right)[\mathrm{OH}] .\end{aligned}$

In this work, the VOC ratio employed is benzene/toluene, as their emission profiles are well-described and reflect the vehicular emissions that form a principal pollution source in the upwind emission area. Measurements of the ratio of benzene/toluene have been made in many locations, some of which are reviewed by Roberts et al. (1984). In this work, we use initial ratios taken from the London Wide Benzene Diffusion Tube Survey Annual Report of 2002, which found mean benzene/toluene ratios for central London of 0.19 and 0.23 depending on the measurement methods used.

Figure 1 shows the calculated photochemical age using Eq. (2), rate constants for benzene and toluene reactions with $\mathrm{OH}$ from the literature (Atkinson, 1994) and a range of $\mathrm{OH}$ concentrations and initial ratios. The initial ratios range from 0.19 to 0.23 as reported above. OH concentrations were measured at the field site, with a mean average for the project of $1.28 \times 10^{6}$ molecules $/ \mathrm{cm}^{3}$. However, Heard et al. (2004) performed a detailed study of $\mathrm{OH}$ concentrations in the major city of Birmingham, UK, which reports summer day-time concentrations between 2 and $3 \times 10^{6}$ molecules $/ \mathrm{cm}^{3}$. It is possible that the values of $\mathrm{OH}$ measured at the site were lower than those over London, so lifetime calculations have to take into account an appropriate range of values. The shaded area in the figure represents the range of values calculated using the ratios mentioned above, with a range of $\mathrm{OH}$ concentration from 1.28 to $3 \times 10^{6}$ molecules $/ \mathrm{cm}^{3}$.
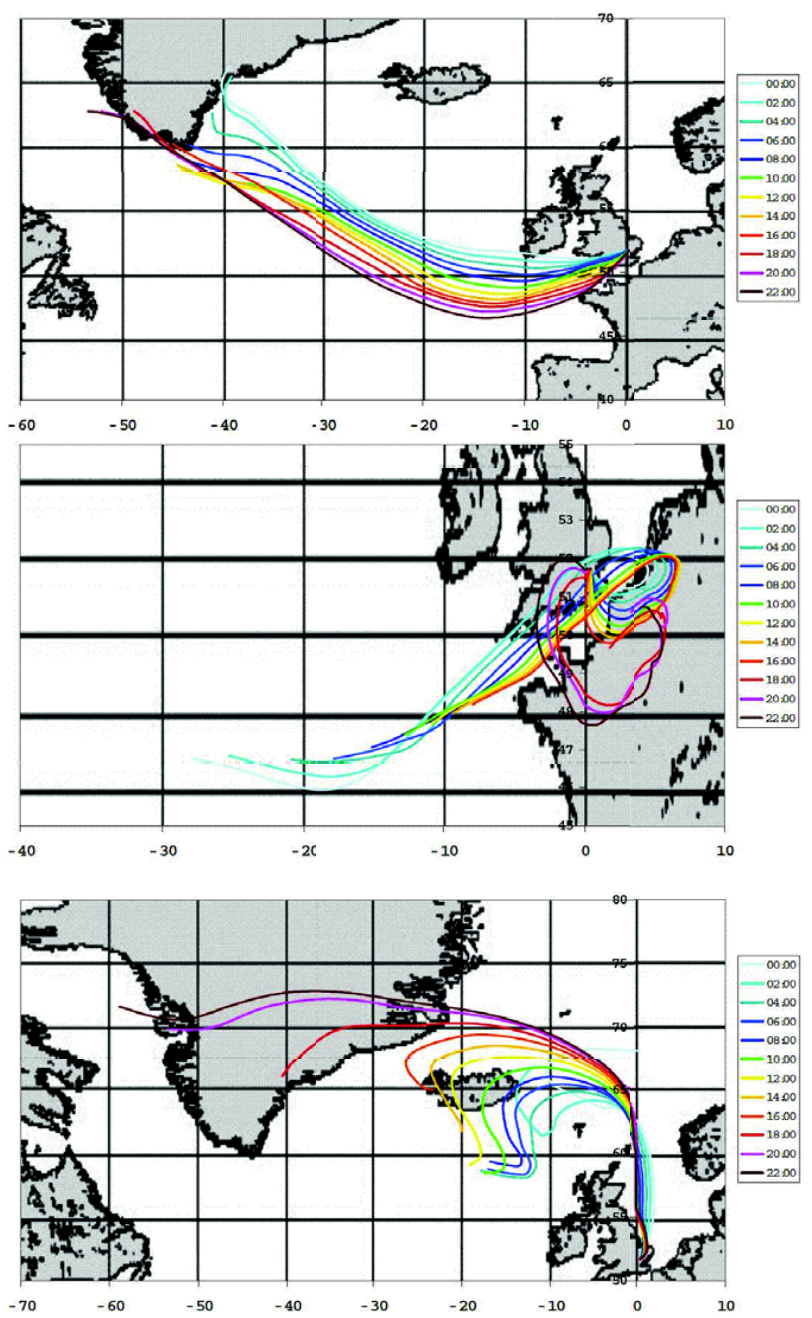

Fig. 2. Representative back trajectories as calculated for the TORCH sampling site by the HYSLPIT model for the Atlantic South Westerly, European Anticyclonic and Arctic Influenced air masses.

\section{Air mass characterisation}

Three distinct time periods were chosen within the TORCH 1 project time frame for which the air masses sampled have both different source regions and exposure to differing degrees of photochemical transformation. Other periods were identified within the project timeframe, but were not suitable for analysis for a combination of reasons: i) The conditions were not constant over a significant time period; ii) Data coverage was not sufficient to perform analysis; iii) Local sources influenced the measurements, so a study of advected air could not be undertaken. The periods chosen were: 1) Atlantic South Westerly (AtlSW) - 28 July to 1 August inclusive; 2) European Anticyclonic Event -6 to 10 August inclusive; and 3) Arctic Source (with local influences) - 26 to 30 August inclusive. 


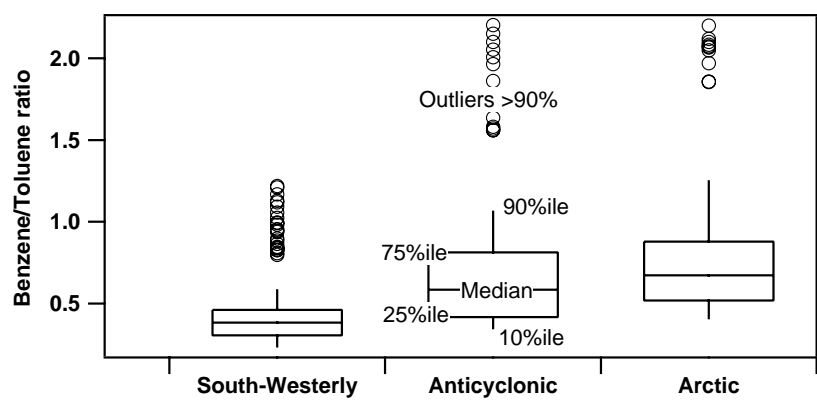

Fig. 3. Box and whiskers plot showing the statistical variation in the Benzene/Toluene ratio during the three different air masses. The lowest ratio (shortest photochemical lifetime) is observed in the Atlantic South Westerly case.

The first period represents the only time in the campaign where a steady south westerly flow was observed for a significant length of time. The air mass has resided over the Atlantic Ocean for the previous 5 days prior to advection to the site over Greater London. As a result, the air mass at the sampling site represented clean marine air exposed to a large urban emissions plume, with potential for atmospheric transformations occurring during advection from London.

The second time period, the European Anticyclonic Event (EuroStag), represents that part of project during which Northern Europe was dominated by a large, stagnant, anticyclonic weather system, and for which, as a result of this weather pattern, the air mass had been circling over Europe for a few days prior to reaching the sampling site. This air mass had been both exposed to significant emissions and to a much greater degree of photochemical processing prior to sampling than in the AtlSW case. The period was dominated by hot, bright weather conditions, with temperatures reaching a maximum of $36^{\circ} \mathrm{C}$ on 9 August. As a result, radical concentrations and rates of cycling were enhanced relative to the AtlSW period.

The final period selected came right at the end of the campaign and represents a period of Arctic influence, where the air reaching the sampling site had been advected from the Arctic region, traveling south over the North Sea, then finally over the rural region of East Anglia for about $200 \mathrm{~km}$ to the sampling location. This exposed clean marine air to small, local, intermittent emission sources for the few hours directly before advection to the sampling site.

Representative back trajectories were used to give an indication of the source regions of the sampled air masses for each period, as shown in Fig. 2.

Figure 3 shows the statistical variation observed in the benzene/toluene ratio for the three air masses. The lowest ratio is observed in the Atlantic South Westerly case, indicating that this air mass has been exposed to significantly less photochemical transformation than in the European Anticyclonic event or the Arctic source air mass.

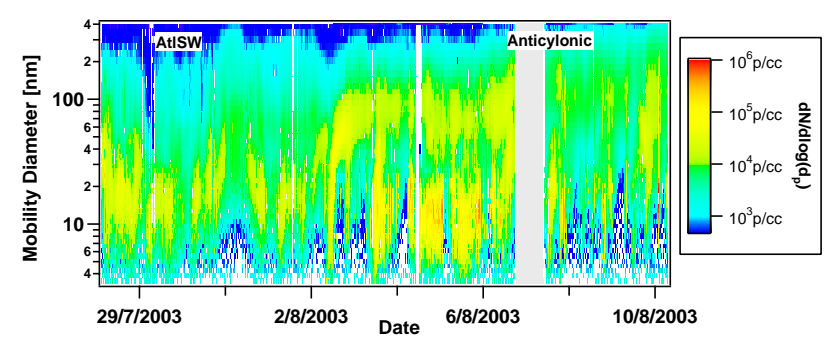

Fig. 4. Variation in the size distribution of the aerosol at the TORCH project as measured by the DMPS.

\subsection{Size distribution}

Figure 4 shows a time series of the dry particle size distribution measured by the DMPS. During the Atlantic South Westerly, the distribution is variable, but in general the highest concentrations are found in the Aitken mode between a mobility diameter of 10 and $50 \mathrm{~nm}$. In contrast, during the Anticyclonic period the particles exhibit a more intermittent, broader distribution. Fresh traffic emissions are predominantly in the Aitken mode (Kittelson, 1998), which could explain the dominance of the Aitken mode during the Atlantic South Westerly situation at the TORCH sampling site. These observations broadly agree with previous studies on aerosol size distribution (many of which are collated in van Dingenen et al. (2004), and give evidence that a single source of urban generated particles is dominating the distribution during the Atlantic South Westerly situation.

\subsection{Hygroscopic properties}

Figure 5 shows individual growth factor distributions during the Atlantic South-Westerly and European Anticyclonic periods for the 7 dry diameters measured. These have been retrieved using the Optimal Estimation Method (OEM) software described by Cubison et al. (2005), which attempts to eliminate the effect of the HTDMA transfer function during the inversion process. The OEM combines a weighted mean of the measurements and a best estimate, a priori, distribution to return contributions to the true atmospheric growth factor distribution in optimally-separated bins. It has the advantage that it retrieves the shape and width of the growth factor distributions as well as the position of the centre of the growth modes. The OEM also allows for an explicit error analysis of the retrieved distributions, calculating contributions to the total error from the measurement uncertainty, errors in the forward model used in the inversion and the so-called smoothing error, which is a result of the under-constrained inversion procedure. In an under-constrained problem there exists a null space - those parts of the measurement space for which we have no information due to the non-continuous nature of the measurements. This induces an inherent uncertainty in the retrieved distribution, and any attempt to retrieve 
a profile with a growth factor resolution that is finer than the information content available in the measurements will result in a retrieved profile that displays oscillatory behaviour (numerical noise). It is thus important to interpret the retrieval carefully, in order to distinguish between the true physical distribution and any artifacts that may have been induced in the retrieval process.

In this work, the optimal bin width for the retrieved distributions over the project time-scale was determined at $g_{90} \sim 0.2$; however, when averaging over many individual measurement cycles, it is possible that some numerical noise be reflected in the averaged distribution depending on the nature of each individual measurement distribution., in this work separated by $\mathrm{g}_{90} \sim 0.2$. A retrieved distribution showing contributions in only one bin therefore reflects a narrow growth mode where the particles exhibit values of $g$ that differ by less than the resolution of the instrument. In contrast, a retrieval showing contributions in several bins reflects a broad atmospheric growth factor distribution. The plots in Fig. 5 show both all the individual contributions to the atmospheric growth factor distribution over the AltSW or Anticyclonic period (left), and representative individual measurements in time (right). It is important to note that a few high $\mathrm{g}_{90}$ values for the small particles, particularly for $\mathrm{g}_{90}>1.5$ at $27 \mathrm{~nm}$ dry diameter, may be due to numerical noise in the retrievals. Consideration of the representative individual retrievals shows that the magnitude of this noise is small relative to the calculated error in the retrieval, thus the contribution to the growth factor distribution at these high values is considered negligible.

In both periods, the hygroscopicity of the soluble, morehygroscopic particles increases with increasing particle diameter, consistent with results from previous studies (e.g. Swietlicki et al., 1999). For particles between 89 and $360 \mathrm{~nm}$ diameter, the distributions are generally bi-modal during the south-westerly period, with an external mixture of both less- and more-hygroscopic modes. The individual distributions highlight these observations, showing contributions to the hygroscopic growth factor distribution in more than one growth factor bin. However, during the anticyclonic period, for a given point in time, the growth factor distribution is narrow and monomodal, and exhibits greater temporal variability in the model growth factor than in the south-westerly period.

In summary, there is a change from externally mixed aerosol to a more internally mixed state when changing from air masses having experienced relatively fresh injection of pollution (London area, $50 \mathrm{~km}$ upwind) to those well removed from local sources. The more-hygroscopic mode presents some variations in its hygroscopicity, but does not appear to radically change between the air masses. The omnipresent nature of the more-hygroscopic mode for the larger sizes during the TORCH campaign is consistent with the common observation of such a mode in the hygroscopicity at many previous studies at diverse locations (e.g. Vakeva et
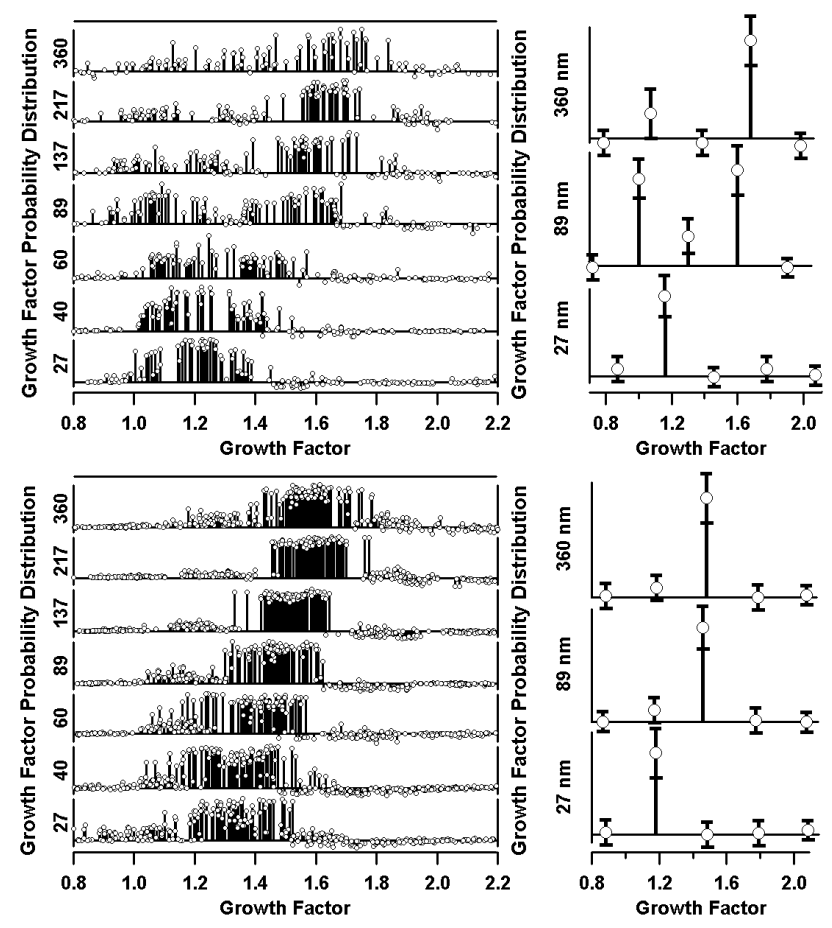

Fig. 5. All the individual (left) and representative individual (right) growth factor distributions, at $90 \% \mathrm{RH}$, for the Atlantic SouthWesterly (top) and European Anticyclonic (bottom) periods for different dry particle diameters (indicated on the vertical axes, nm). The cumulative plots show all the retrieved distributions during these periods together, giving an indication of the variability of the modes. The individual plots highlight a single retrieval from one point in time, including total error in retrieval space.

al., 2002; Cocker et al., 2001; Zhou et al., 2002; Swietlicki et al., 2000).

\subsection{Chemical composition}

The average size-resolved chemical composition was ascertained using the AMS, as shown in Fig. 6.

Both the south-westerly and anticyclonic periods exhibit a mixed organic-inorganic mass mode at a vacuum aerodynamic diameter of $d_{v a} \sim 500 \mathrm{~nm}$, although the mass loadings are significantly higher in the anticyclonic case. Here, there is a shoulder visible in the organic mass distribution towards the smaller sizes, but as the AMS measures the ensemble particle population, it is difficult to state with certainty that this represents an externally mixed organic mode. It could also be that the variation in composition with size is a reflection of the changing composition as the particles increase in size with age in the atmosphere. The single mode observed in the HTDMA during this period is also suggestive of an internally mixed state. However, in the south-westerly, the external mixture visible in the HTDMA measurements is represented in the AMS by an externally mixed organic mode visible at the smaller diameters, indicative of fresh urban emissions. 


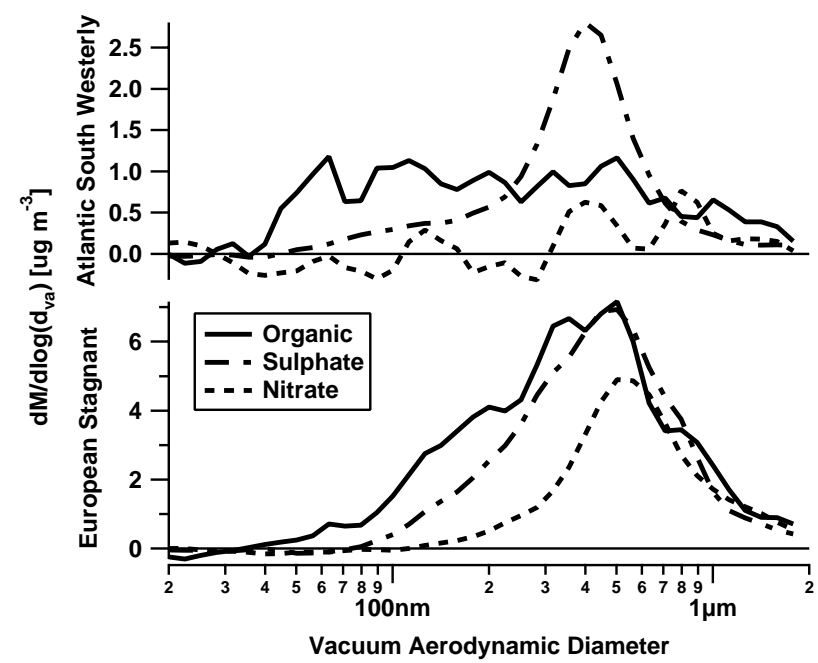

Fig. 6. Average time-of-flight (size resolved) distributions from the AMS for the Atlantic South Westerly (top) and European Anticylonic (bottom) periods defined during the TORCH campaign.

Measurements of a broad mixed organic-inorganic mode were observed at $600-700 \mathrm{~nm}$ aerodynamic diameter in Manchester city centre (Allan et al., 2003b) and 400-600 nm aerodynamic diameter in Vancouver, Canada and Pittsburgh, USA (Alfarra et al., 2004; Zhang et al., 2005a, 2005c), all of which were attributed to advection of PM from the regional area. Distributions displaying a small diameter organic mode in addition to a mode attributed to the regional PM distribution are often visible during urban measurements (e.g. Allan et al., 2003b), although the mass loadings expected in city centre locations would be much higher than observed in the south-westerly air mass at TORCH. Thus, whilst the shape of the size resolved chemical composition remains largely unchanged during advection from London to the sampling site (a timescale of $\sim 2-4 \mathrm{~h}$ ), processes such as dispersion are acting to decrease the absolute mass loadings of the urban generated mode.

The influence of the urban organic and mixed organicinorganic modes was shown to be size-dependent during the TORCH project. Figure 7 shows the organic to inorganic mass ratio as a function of vacuum aerodynamic particle diameter during the Anticyclonic period, indicating that the influence of the organic component decreases with increasing particle diameter. Similar analysis proved difficult to compute in the AtlSW period owing to the lower mass loadings and therefore increased counting statistics error.

Figure 7 indicates that, as the lifetime of aerosol in the atmosphere increases, and the aerosol grow in size from atmospheric processes such as condensation, the organic: inorganic ratio decreases. Thus the increase in solubility of the particles observed with increasing diameter may result from the observed increase in inorganic fraction with particle size. These results indicate a reduced influence on the parti-

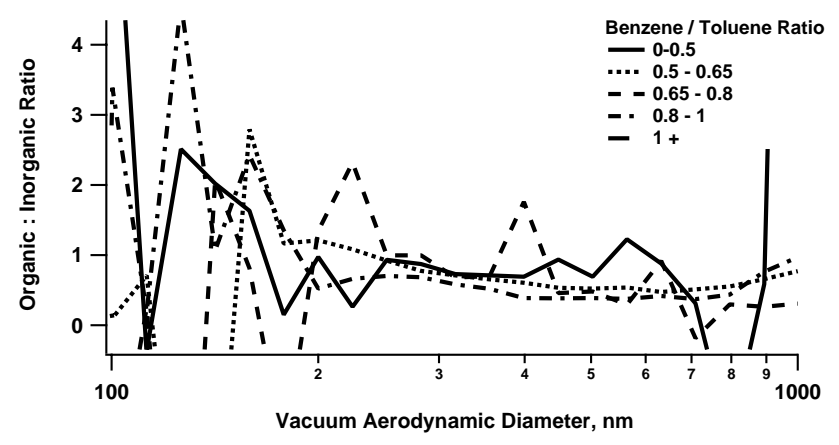

Fig. 7. Organic:Inorganic mass ratio as a function of particle diameter during the European Anticyclonic event at the TORCH project.

cle mass from organics under the impact of atmospheric processing, as the higher organic content in the smaller, younger particles suggests that that the production of secondary organic aerosol occurs faster than the conversion of $\mathrm{SO}_{2}$ to sulphate. Therefore the hygroscopicity may be controlled by the source contributions of these species along the history of the air parcel, for they determine the organic:inorganic mass ratio. The differences between the AltSW and Anticyclonic mass distributions can only be explained if either the Anticylonic period experiences a different source profile, or if atmospheric processing is acting to transform the source mass profile in some way. A broadly similar source profile would be expected for an air mass passing over London and one exposed to multiple urban sources over Western Europe, thus it would appear that atmospheric processing, with different processing timescales for different precursors, is responsible for the observed change in composition with size in Fig. 7. This points to atmospheric processing impacting on the aerosol mass distribution over time, however in the AtlSW case there has not been sufficient time for processes to result in significant changes in the observations. For aerosol species such as sulphate which are known to originate from heterogeneous reactions involving gas-phase precursors (see e.g. Luria and Sievering, 1991), the differences in the mass distributions between the two periods do indicate that photochemical conversions are taking place on a time scale equivalent to the photochemical lifetime of the European Anticyclonic event, i.e. about 1 or 2 days.

\subsection{Organic speciation}

A recent development in analysis of AMS measurements is the ability to split the contribution to the observed organic loading into hydrocarbon-like organic aerosol (HOA) and oxygenated (OOA) fractions (Zhang et al., 2005b, 2005c). The AMS gives an ensemble mass spectrum for a large range of $m / z$ 's, which can be used to segregate the contributions from the two fractions. Certain mass fragments, e.g. $\mathrm{m} / \mathrm{z}$ 57 , are indicative of hydrocarbon-like structures (typically $\mathrm{C}_{4} \mathrm{H}_{9}^{+}$), whereas others, e.g. $\mathrm{m} / z$ 44, (typically the $\mathrm{CO}_{2}^{+}$ion), 


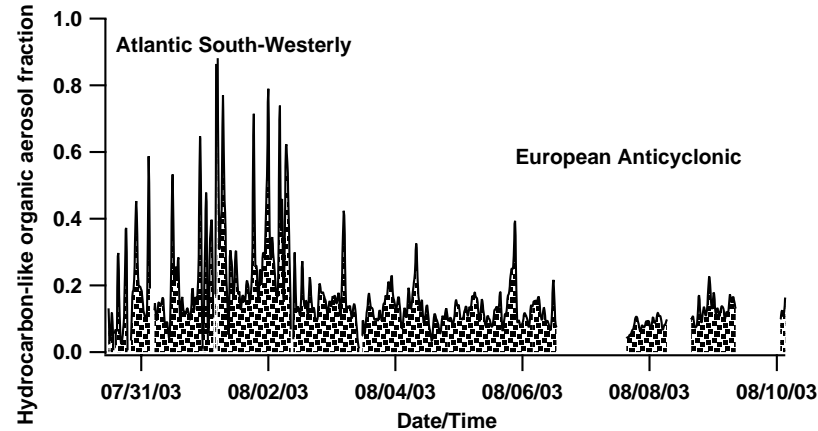

Fig. 8. Time series of the hydrocarbon-like organic aerosol fraction of the total organic content.

only arise from oxygenated compounds (Alfarra et al., 2004). It is therefore possible to estimate the relative contributions from fresh emissions, which tend to be hydrocarbon-like in nature, and those organics which have been oxygenated through atmospheric transformations such as gas or particle phase photochemical reactions.

Figure 8 shows the time series of the fraction of the organic mass observed in the AMS which can be considered as HOA. During the Atlantic South-Westerly period, 20\% of the organics can be considered as HOA, although there are many high, short-lived peaks in the HOA fraction, probably arising from local sources. In contrast, the HOA fraction observed during the anticyclonic period maintains relatively constant, lower values. Similar analysis on AMS measurements taken in Manchester city centre shows a HOA fraction between approximately 20 and $50 \%$. Neglecting the outliers during the south-westerly, the HOA fraction is somewhere between the city centre and anticyclonic values. Assuming that the HOA fraction in Greater London will be similar to that of the urban Manchester measurements, the reduction in the HOA fraction may be due to either dilution or processing, through addition of oxygenated material onto the pollution aerosol. Given the absence of a hydrophobic mode in the background the latter is more likely.

\section{Classification by VOC ratio}

To improve the estimate of the required time scale for processing of the urban aerosol to the aged background state, it is necessary to analyse the data in a more selective manner than categorisation by air mass. The approach taken here to determine mean average distributions of the hygroscopic properties and HOA/OOA components as a function of the benzene/toluene ratio. Through consideration of the observed differences as the ratio increases, it is possible to determine the ratio at which the distributions match those of the ubiquitous continental background state.

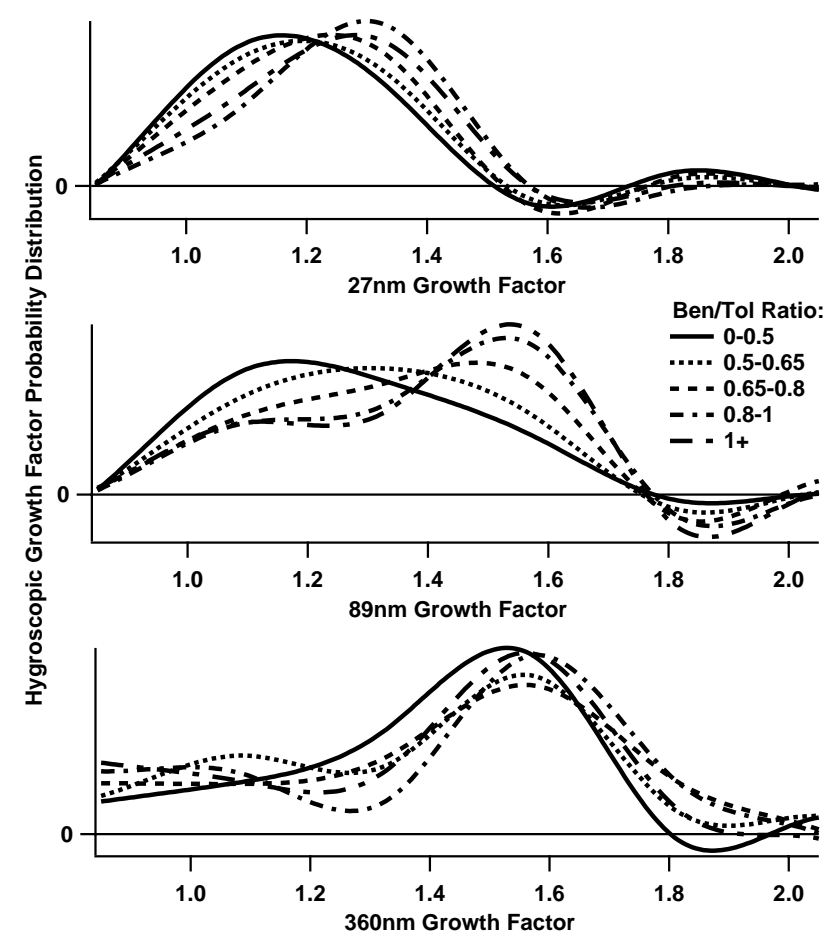

Fig. 9. Mean retrieved hygroscopic growth factor distributions, at $90 \% \mathrm{RH}$, from the entire TORCH campaign averaged as a function of the VOC ratio benzene/toluene as a marker of photochemical age. Particle dry diameter is indicated on the $\mathrm{x}$-axis. Both the negative probabilities at all sizes and growth factors, and positive contributions for $\mathrm{g}>1.7$ at $27 \mathrm{~nm}$ arise from numerical noise induced by the retrieval process. The magnitude of the oscillations is smaller than the standard deviation on the probability distribution in the individual retrievals.

\subsection{Hygroscopic properties}

The retrieved hygroscopic growth distribution was averaged according to the mean benzene/toluene ratio during the period of the HTDMA measurement. The results of this analysis procedure for the duration of the campaign are shown in Fig. 9.

At $27 \mathrm{~nm}$ dry diameter, the single less-hygroscopic mode increases in hygroscopicity with increasing VOC ratio, with a change in growth factor of $\sim 20 \%$ over the range of VOC ratios measured. The contributions to the growth factor distribution above $\mathrm{g}_{90}=1.7$ are artefacts induced by numerical noise in the retrieval process, their associated error is larger than their magnitude and they are thus considered negligible. There may also be an increase in the growth factor of the single more-hygroscopic mode observed at $360 \mathrm{~nm}$, but it is not possible to state this for certain within the resolution of the retrieval ( $\sim 0.18$ in growth factor space). In the $89 \mathrm{~nm}$ case, the more-hygroscopic mode becomes more prominent with increasing VOC ratio. Below a benzene/toluene ratio of 0.65 the less-hygroscopic mode appears dominant, with the 


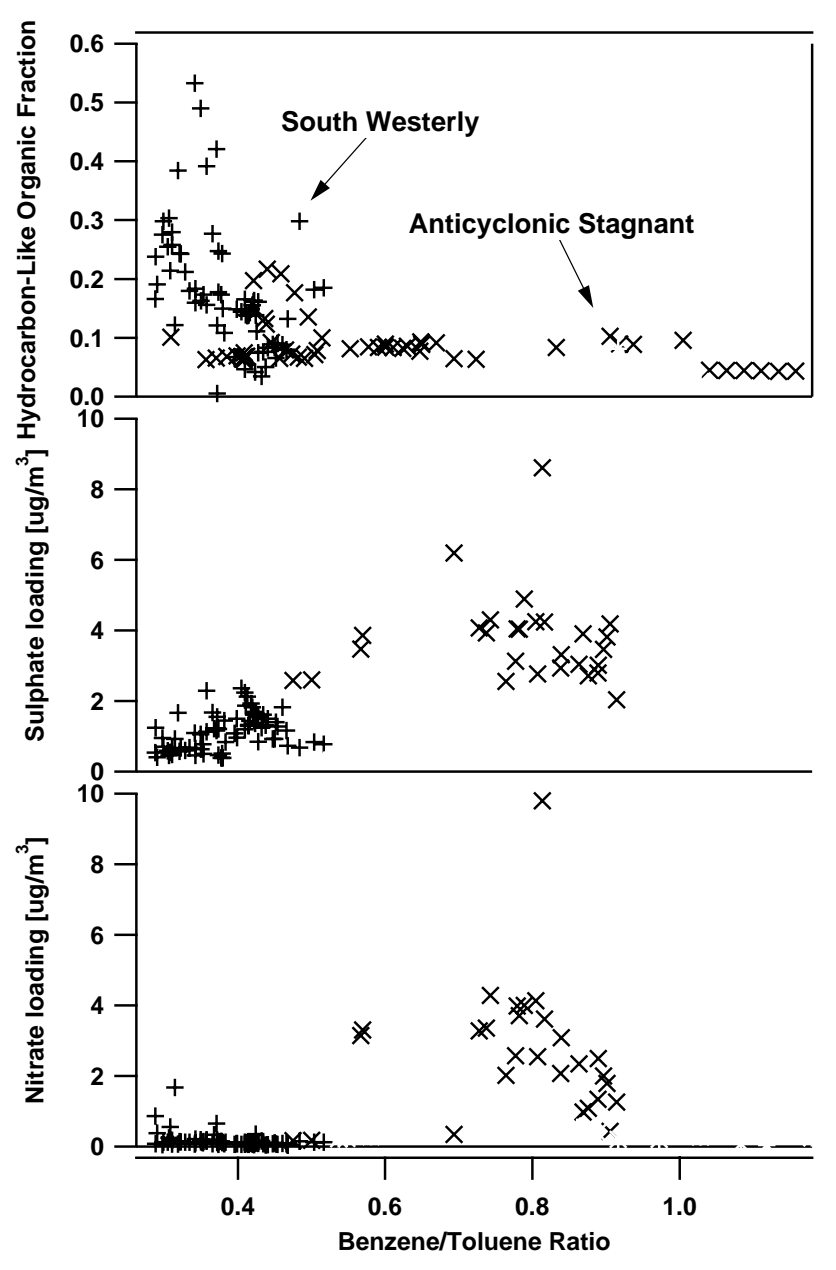

Fig. 10. Correlation between the hydrocarbon-like organics, sulphate and nitrate aerosol content and the benzene/toluene ratio as a function of air mass during the TORCH campaign.

more-hygroscopic mode becoming apparent above a VOC ratio of about 0.8 . This change represents a shift in mode diameter of the humidified particles of $40 \%$, from $\sim 100 \mathrm{~nm}$ to $\sim 140 \mathrm{~nm}$.

The differences in the results of this analysis on the different particle dry diameters reflects the age of the particles within the atmosphere, with the $27 \mathrm{~nm}$ diameter particles being younger than the $89 \mathrm{~nm}$, and the $360 \mathrm{~nm}$ diameter particles already likely being several days old, based on the modal diameter of the broad regional background mode reported by Alfarra et al. (2004). The observation that the $89 \mathrm{~nm}$ diameter particles show a much more dynamic change with VOC ratio than at $360 \mathrm{~nm}$ or $27 \mathrm{~nm}$ may be a function of the range of photochemical age of the air masses observed. The $360 \mathrm{~nm}$ particles may be older than the most recent large scale injection of pollution, implied from the benzene/toluene ratios observed, whilst the $27 \mathrm{~nm}$ diameter particles may have a lifetime representative of a benzene/toluene ratio less than 0.5.
Thus the particles at both diameters would show little or no change in solubility with the observed VOC ratio, whilst the $89 \mathrm{~nm}$ diameter particles may be several hours old in photochemical age, and thus of the same timescale as the VOC ratios.

Similar analysis performed just over the periods of the air masses described above shows very similar results for the Atlantic South-Westerly situation, but no significant changes with VOC ratio in the European Anticyclonic event. This is probably due to the advection trajectories of the two different air masses. In the south-westerly air flow, initially clean air is advected over London to the site, so the VOC ratio more accurately reflects the photochemical age of the air mass than in the anti-cyclonic situation, where multiple sources of all components may be contributing and thus it is more difficult to establish relationships to the aerosol behaviour.

\subsection{HOA and OOA}

The top plot in Fig. 10 shows the correlation between the hydrocarbon-like fraction of the organic aerosol content and the benzene/toluene VOC ratio. The negative correlation at low VOC ratios levels out at a benzene/toluene ratio of $\sim 0.6$. From Fig. 1, this corresponds to a photochemical age of about 1 or 2 days.

Prior to this timescale, the measurements indicate that, as the benzene to toluene ratio increases, a gradually larger fraction of the aerosol organic content is oxygenated, by which it is speculated that most organic molecules contain one or more oxygenated groups, although this cannot be proven with AMS data only. Condensation of secondary organic aerosol (SOA), which adds oxygenated aerosol mass and thus reduces the HOA fraction, is likely the dominant process that causes this transformation. Heterogeneous and particlephase chemical reactions of hydrocarbon-like aerosol may also alter its composition (Molina et al., 2004), though these cannot give rise to a significant increase in mass. Indeed Zhang et al. (2005c) and Volkamer et al. (2006) recently reported that no appreciable oxidation of HOA occurred within a time scale of several hours in Pittsburgh and Mexico City, respectively. Furthermore, recent studies have concluded that primary aerosols cannot explain the amount of organic mass observed at urban locations (Volkamer et al., 2006), and at rural and remote locations (de Gouw et al., 2005; Heald et al., 2005).

All these processes tend to increase the oxygenated content of the aerosol organics, such that after $\sim 1-2$ days photochemical age, virtually all the organic content is oxygenated in nature. To highlight the state of oxygenation of the aerosol that had been exposed to $\sim 1-2$ days of atmospheric processing time, the methodology of Zhang et al. (2005c) was used to estimate the oxygen to carbon $(\mathrm{O}: \mathrm{C})$ molar ratio for the European Anticyclonic event at the TORCH campaign, returning a value of 0.83 with a standard deviation of $9 \%$. This is very similar to the value of 0.8 reported by 
Zhang et al. (2005c) for the OOA fraction observed at Pittsburgh (USA). This supports the hypothesis that most of the OOA organic molecules contain a significant number of oxygenated groups.

There does, however, remain a small residual HOA fraction even at the higher VOC ratios. This may be due to the inability of the analytical technique used to fully separate the fractions according to their representative fragmentation patterns or it may be a real atmospheric phenomenon, and further work is underway to examine this aspect further.

In addition, Fig. 10 also shows that the sulphate and nitrate aerosol mass tend to increase as the benzene/toluene ratio increases, reflecting the influence of the condensation of these species onto the existing aerosol population over time. There may be some evidence for nitrate fraction becoming smaller over longer timescales, where long range transport has played a significant role and is likely to be dominated by acidified sulphate aerosol. However, it should be noted that the increase of sulphate mass in the aerosol burden may not necessarily be coupled to the VOC ratio, for it will be influenced effects such as cloud processing. In addition, the source footprint of $\mathrm{SO}_{2}$ may be significantly different to the assumed source region of the VOCs, for other sources, such as power plants, may add to the urban $\mathrm{SO}_{2}$ emissions.

Together, the increase in the oxygenated fraction of the aerosol organics and condensation of inorganics and SOA impacts on the aerosol hygroscopic properties, as indicated by Fig. 11, which shows the hygroscopic growth distribution as a function of the HOA component of the organic aerosol mass. In common with the VOC ratio analysis shown in Fig. 9, the differences observed over the different dry diameters reflect the length of exposure of the particles to atmospheric processing. Once again, the contributions to high $\mathrm{g}_{90}$ values at $27 \mathrm{~nm}$ are induced by noise in the retrieval and considered negligible within the associated errors. The Aitken mode particles have a short residence time in the atmosphere and thus are comprised almost entirely of hydrophobic HOA, whereas the $89 \mathrm{~nm}$ particles are undergoing the transformation to the OOA and hygroscopic inorganic dominated accumulation mode.

The observations suggest that the timescale of atmospheric processing of aerosol is such that particles of $\sim 100 \mathrm{~nm}$ in diameter exhibit the most dynamical behaviour, as sulphate/ nitrate mass and SOA are condensed onto the aerosol and photochemical processes may act to oxygenate the aerosol organics. Together these processes act to gradually increase the aerosol hygroscopicity in parallel with the increase in aerosol mass, and therefore diameter, through condensation. Thus the initially fresh, hydrocarbon-like less-hygroscopic particles of nucleation mode diameter are gradually transformed to large soluble particles with a significant inorganic content, over a timescale indicated by the VOC ratios to be of the order 1-2 days.

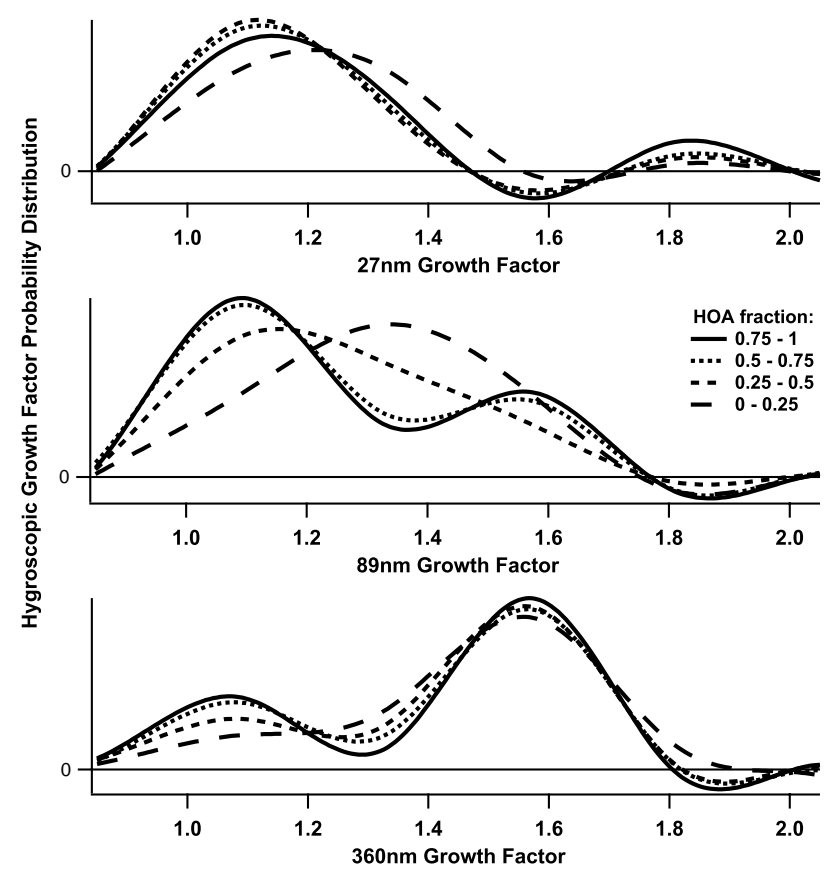

Fig. 11. The transformation of the hygroscopic growth factor, at $90 \% \mathrm{RH}$, of the ambient aerosol with increasing oxygenated organic content. Both the negative probabilities at all sizes and growth factors, and positive contributions for $\mathrm{g}>1.7$ at $27 \mathrm{~nm}$ arise from numerical noise induced by the retrieval process. The magnitude of the oscillations is smaller than the standard deviation on the probability distribution in the individual retrievals.

\section{Conclusions}

It has been previously reported that there is a transition from an external mixture of particles in urban areas to a single, internal, processed mixture in background locations (see e.g. Svenningsson et al., 1994; Swietlicki et al., 2000). However, the time scales for this processing have not previously been investigated as a continuous function of photochemical age.

Recent work in the literature describes modelling studies which attempt to estimate the time scales for similar transformations to those investigated here, such as the processing of soot (Riemer et al., 2004) and organics (Reddy and Boucher, 2004; Cooke et al., 2002). The transformation of organic matter from the less- to the more-hygroscopic mode was estimated to occur in $\sim 1-3$ days (Reddy and Boucher, 2004; Cooke et al., 2002), and soot between $8 \mathrm{~h}$ and 2 days (Riemer et al., 2004). We present measurements which indicate that transformations of this nature in the hygroscopicity occur on this time scale in the real atmosphere. We have given evidence to show that there is a very common, processed background distribution, or state, in the aerosol burden that is represented by soluble, mixed inorganic-oxygenated organics in the accumulation mode. In contrast, fresh aerosol emissions in urban areas are shown to be virtually insoluble and are 
dominated by organics with a high fraction of hydrocarbonlike material. The emitted particles are small, in the nucleation or Aitken modes, and are externally mixed with the background aerosol. The fresh particles are acted on by physical and chemical processes as they are advected away from the source area - a combination of dilution, condensation, coagulation and chemical reactions transform these aerosol to the large diameter soluble background distribution over a time scale of approximately 1-2 days.

Several previous AMS studies at Northern Hemisphere mid-latitude locations have all shown a similar large diameter soluble background distribution (Allan et al., 2003b, 2004a; Alfarra et al., 2004; Zhang et al., 2005a, e.g.). As the aerosol enters rural regions biogenic SOA may accumulate on the aerosol and thus further change the physical and chemical properties of the aerosol beyond this timescale. With the current AMS analysis methods, it is possible to clearly separate hydrocarbon-like from oxygenated aerosols (Zhang et al., 2005b), especially in urban areas. Based on both chamber experiments and ambient data, biogenic and anthropogenic SOA spectra, although showing some differences (Bahreini et al., 2005), are more similar to each other than to HOA. Although this is a topic of intense research, biogenic and anthropogenic SOA components cannot be separated reliably from AMS spectra at this time. Therefore it is not presently possible to distinguish if the observation of no further changes in the OOA fraction beyond the 1-2 day timescale is as a result of the lack of further SOA accumulation, or if there is biogenic SOA accumulation which cannot currently be resolved from the anthropogenic SOA component.

The absence of a hydrophobic mode of small particles in the regional background may be due to dilution as air advected downwind of the source region and mixes. However, the urban particles are known to be modified to a morehygroscopic state from studies in closed artificial chambers (Weingartner et al., 1997, 1995), which proves the evolution of such emissions is likely in the atmosphere, therefore providing strong evidence that they can be processed into a state representative of the background distribution. This process has also been proposed by other studies in the literature (e.g. Swietlicki et al., 2000) and used as a parameterisation in a number of global models (e.g. Koch, 2001; Lohmann et al., 2000).

The observations taken in an air mass 1-2 days downwind of a source region presented here exhibit similarities to background sites which are significantly further from source, such as the Jungfraujoch in Switzerland (McFiggans et al., 2005). Therefore, in summary, whilst the effects of individual processes such as condensation and coagulation have not been considered here, in their ensemble, atmospheric transformations of urban aerosol appear to be negligible after $\sim 2$ days, which would allow for a simple representation of the ageing process in regional transport and/or global climate models. The hygroscopic properties of the particles may therefore be described simply by the relative integrated contributions to the condensable flux of organic and inorganic material providing no further source region is intercepted. The approach of the modeling studies of e.g. Reddy and Boucher (2004) who define a characteristic processing time (1/e) for transformation of organics from the less- to the more-hygroscopic fractions, thus broadly agrees with this hypothesis, for after 3 or so characteristic time periods virtually no further changes would be observed.

Though the cloud condensation properties of the aerosol are not explicitly discussed in this paper, the result that particles at $89 \mathrm{~nm}$ diameter exhibit the largest changes in their hygroscopic properties with changing photochemical lifetime in the atmosphere indicates that these ageing processes will have a significant impact on the $\mathrm{CCN}$ number population, and hence cloud droplet number, as these particle sizes are the smallest particles that are likely to be activated into cloud droplets (see e.g. McFiggans et al., 2006; Raymond and Pandis, 2003). Dusek et al. (2006) argue that the aerosol size distribution is a more important parameter than the particle solubility in determining $\mathrm{CCN}$ activation, but present data predominantly from air masses aged $>2$ days and for supersaturations that are much larger than those typically experienced in the atmosphere.

For a data set collected in a similar situation to the TORCH 1 site, they show that the small diameter externally mixed mode activates very poorly indeed. The fractional $\mathrm{CCN}$ activation of the Aitken mode at this site was shown to be roughly $20 \%$ less than the background cases at high supersaturations, and as much as $80 \%$ less at lower supersaturation values that are more atmospherically relevant but remain larger than all but the most vigorous convective clouds. The activation properties of aerosol distributions with strong Aitken modes, as observed at the TORCH site, are greatly influenced by the nature of the organic component (Mircea et al., 2002). After more than 2 days processing time, the aerosol population will have undergone growth by condensation and semivolatile repartitioning and it is likely to more closely resemble an internal mixture and display a more homogeneous solubility. The Dusek et al. (2006) results show that size will become the controlling parameter in $\mathrm{CCN}$ activation under such conditions, but it is known that the chemical nature of the fresh emissions and their state of mixing with respect to the soluble background distribution is an important parameter up until this time. Here we have shown that particles in the $80-120 \mathrm{~nm}$ range, which Dusek et al. (2006) show are crucial for determining CCN activation, are sometimes dominated by processing and sometimes dominated by primary emission.

As these are the smallest particles likely to be activated in real cloud updrafts (see e.g. graph 1a in Dusek et al., 2006), such changes with air mass are likely to have a significant impact on the overall cloud droplet population. 
Acknowledgements. The measurements were supported through the NERC Polluted Troposphere programme. M. J. Cubison was supported during the period of this work through NERC studentship no. 06424 .

Edited by: S. Martin

\section{References}

Alfarra, M., Coe, H., Allan, J., Bower, K., Boudries, H., Canagaratna, M., Jimenez, J., Jayne, J., Garforth, A., Li, S.-M., and Worsnop, D.: Characterization of urban and rural organic particulate in the Lower Fraser Valley using two Aerodyne Aerosol Mass Spectrometers, Atmos. Environ., 38, 5745-5758, 2004.

Allan, J. D., Jimenez, J. L., Williams, P. I., Alfarra, M. R., Bower, K. N., Jayne, J. T., Coe, H., and Worsnop, D. R.: Quantitative sampling using an Aerodyne aerosol mass spectrometer 1. Techniques of data interpretation and error analysis, J. Geophys. Res., 108(D3), 4090, doi:10.1029/2002JD002358, 2003 a.

Allan, J. D., Alfarra, M., Bower, K., Williams, P., Gallagher, M., Jimenez, J., McDonald, A., Nemitz, E., Canagaratna, M., Jayne, J., Coe, H., and Worsnop, D.: Quantitative sampling using an Aerodyne aerosol mass spectrometer 2. Measurements of fine particulate chemical composition in two U.K. cities, J. Geophys. Res., 108(D3), 4091, doi:10.1029/2002JD002359, 2003b.

Allan, J., Delia, A., Coe, H., Bower, K., Alfarra, M., Jimenez, J., Middlebrook, A., Jayne, J., and Worsnop, D.: A generalised method for the extraction of chemically resolved mass spectra from Aerodyne aerosol mass spectrometer data, J. Aerosol Sci., 35, 909-922, 2004b.

Alonso, M., Alguacil, F., Martin, M., Kousaka, Y., and Nomura, T.: Aerosol particle size growth by simultaneous coagulation and condensatioon with diffusion losses in laminar flow tubes, J. Aerosol Sci., 30, 1191-1199, 1999.

Atkinson, R.: Gas-phase tropospheric chemistry of organic compounds, J. Phys. Chem. Ref. Data, Monograph 2, 1-216, 1994.

Barrett, J. and Baldwin, T.: Aerosol nucleation and growth during laminar tube flow - maximum saturations and nucleation rates, J. Aerosol Sci., 31, 633-650, 2000.

Barrett, J. and Baldwin, T.: Aerosol nucleation and growth during laminar tube flow - quenching effects and wall condensation, J. Aerosol Sci., 32, 957-974, 2001.

Barrett, J. and Clement, C.: Growth rates for liquid drops, J. Aerosol Sci., 19, 223-242, 1988.

Berg, O., Swietlicki, E., and Krejci, R.: Hygroscopic growth of aerosol particles in the marine boundary layer over the Pacific and Southern Oceans during the First Aerosol Characterization Experiment (ACE 1), J. Geophys. Res., 103D, 16535-16546, 1998.

Calvert, J.: Hydrocarbon involvement in photochemical smog formation in Los Angeles atmosphere, Environ. Sci. Technol., 10, 256-262, 1976.

Claeys, M., Graham, B., Vas, G., Wang, W., Vermeylen, R., Pashynska, V., Cafmeyer, J., Guyon, P., Andreae, M., Artaxo, P., and Maenhaut, W.: Formation of secondary organic aerosols through photo-oxidation of isoprene, Science, 303, 1173-1176, 2004.

Cocker, D., Whitlock, N., Flagan, R., and Seinfeld, J.: Hygroscopic properties of Pasadena, California aerosol, Aerosol Sci. Technol., 35, 637-647, 2001.
Cooke, W. F., Ramaswamy, V., and Kasibhatla, P.: A general circulation model study of the global carbonaceous aerosol distribution, J. Geophys. Res., 107(D16), 4279, doi:10.1029/2001JD001274, 2002.

Covert, D. and Heintzenberg, J.: Size distributions and chemical properties of aerosol at Ny-Alesund, Svalbard, Atmos. Environ., 27A, 2989-2997, 1993.

Cubison, M., Gysel, M., and Coe, H.: A modified hygroscopic tandem DMA and a data retrieval method based on optimal estimation, J. Aerosol Sci., 36, 846-865, 2005.

DeCarlo, P., Slowik, J. G., Worsnop, D. R., Davidovits, P., and Jimenez, J. L.: Particle Morphology and Density Characterization by Combined Mobility and Aerodynamic Diameter Measurements. Part 1: Theory, Aerosol Sci. Technol., 38, 11851205, 2004, doi:10.1080/027868290903907.

Donaldson, K., Li, X., and MacNee, W.: Ultrafine (nanometre) particle mediated lung injury, J. Aerosol Sci., 29, 553-560, 1998.

Drewnick, F., Schwab, J., Jayne, J., Canagaratna, M., Worsnop, D., and Demerjian, K.: Measurement of Ambient Aerosol Composition During the PMTACS-NY 2001 Using an Aerosol Mass Spectrometer. Part I: Mass Concentrations, Aerosol Sci. Technol., 38(S1), 92-103, 2004.

Dusek, U., Frank, G. P., Hildebrandt,L., Curtius, J., Schneider, J., Walter, S., Chand, D., Drewnick, F., Hings, S., Jung, D., Borrmann, S. and Andreae, M.O.: Size matters more than chemistry for cloud-nucleating ability of aerosol particles, Science, 312(5778), 1375-1378, 2006.

Ghio, A. and Devlin, R.: Inflammatory lung injury after bronchial instillation of air pollution particles, Am. J. Resp. Crit. Care, 164(4), 704-708, 2001.

Heard, D. E., Carpenter, L. J., Creasey, D. J., Hopkins, J. R., Lee, J. D., Lewis, A. C., Pilling, M. J., Seakins, P. W., Carslaw, N., and Emmerson, K. M.: High levels of the hydroxyl radical in the winter urban troposphere, Geophys. Res. Lett., 31, L18112, doi:10.1029/2004GL020544, 2004.

Hopkins, J., Lewis, A., and Reid, K.: A two-column method for long-term monitoring of nonmethane hydrocarbons (NMHCs) and oxygenated volatile organic compounds (o-VOCs), J. Environ. Monitor., 5, 8-13, 2003.

Horak Jr., F., Frischer, T., Studnicka, M., Gartner, C., Hauck, H., and Preining, O.: The chemical composition of particulate matter has a short term effect on the lung function of pre-school children, Eur. Respri. J., 18, Suppl. 33, 128, 2001.

IPCC: Climate change 2001: Scientific basis. Third assessment of the Inter-govermental Panel on Climate Change, Cambridge, 2001.

Jacobson, M. Z.: Fundamentals of Atmospheric Modelling, Cambridge University Press, Cambridge, UK, 1999.

Jayne, J., Leard, D., Zhang, X., Davidovits, P., Smith, K., Kolb, C., and Worsnop, D.: Development of an aerosol mass spectrometer for size and composition analysis of submicron particles, Aerosol Sci. Technol., 33, 49-70, 2000.

Jimenez, J. L., Bahreini, R., Cocker III, D. R., Zhuang, H., Varutbangkul, V., Flagan, R. C., Seinfeld, J. H., O’Dowd, C. D., and Hoffmann, T.: New particle formation from photooxidation of diiodomethane (CH2I2), J. Geophys. Res., 108(D10), 4318, doi:10.1029/2002JD002452, 2003.

Kim, C. and Jaques, P.: Respiratory dose of inhaled ultrafine particles in healthy adults, Philos. Trans. R. Soc. Lond. Ser. A-Math. 
Phys. Eng. Sci., 358, 2693-2705, 2000.

Kittelson, D.: Engines and nanoparticles: A review, J. Aerosol Sci., 29, 575-588, 1998.

Kleinmann, L., Daum, P., Lee, Y.-N., Nunnermacker, L., Springston, S., Weinstein-Lloyd, J., Hyde, P., Doskey, P., Rudolph, J., Fast, J., and Berkowitz, C.: Photochemical age determinations in the Phoenix metropolitan area, J. Geophys. Res., 108(D3), 4096, doi:10.1029/2002JD002621, 2003.

Koch, D.: Transport and direct radiative forcing of carbonaceous and sulphate aerosols in the GISS GCM, J. Geophys. Res., 106D, 311-322, 2001.

Kulmala, M.: How particles nucleate and grow, Science, 302, 10001001, 2003.

Kulmala, M., Majerowicz, A., and Wagner, P.: Condensational growth at large vapour concentration: Limits of applicability of the Mason equation, J. Aerosol Sci., 20, 1023-1026, 1989.

Kulmala, M., Laakso, L., Lehtinen, K., Riipinen, I., Del Maso, M., Anttila, T., Kerminen, V.-M., Horrak, U., Vana, M., and Tammet, H.: Initial steps of aerosol growth, Atmos. Chem. Phys., 4, 25532560, 2004a.

Lee, A., Bartle, K., and Lewis, A.: A Model of Peak Amplitude Enhancement in Orthogonal Two-Dimensional Gas Chromatography., Analytical Chem., 73, 1324-1329, 2001.

Lee, K.: Change of particle size distribution during Brownian coagulation, J. Colloid Interf. Sci., 92, 315-325, 1983.

Lewis, A., Bartle, K., McQuaid, J., Pilling, M., Seakins, P., and Ridgeon, P.: Atmospheric monitoring of volatile organic compounds using programmed temperature vaporisation injection, J. High Res. Chromatog., 19, 686-690, 1996.

Lewis, A., Carslaw, N., Marriott, P., Kinghorn, R., Morrison, P., Lee, A., Bartle, K., and Pilling, M.: A larger pool of ozoneforming carbon compounds in urban atmospheres, Nature, 405, 778-781, 2000.

Limbeck, A., Kulmala, M., and Puxbaum, H.: Secondary organic aerosol formation in the atmosphere via heterogeneous reaction of gaseous isoprene on acidic particles, Geophys. Res. Lett., 30(19), 1996, doi:10.1029/2003GL017738, 2003.

Lohmann, U., Feichter, J., Penner, J., and Leaitch, R.: Indirect effect of sulphate and carbonaceous aerosols: a mechanistic treatment, J. Geophys. Res., 105D, 193-206, 2000.

Luria, M. and Sievering, H.: Heterogeneous and homogeneous oxidation of SO2 in the remote marine atmosphere, Atmos. Environ., 25A, 1489-1496, 1991.

Malet, J., Alloul, L., Michielsen, N., Bouland, D., and Renoux, A.: Deposition of nanosized particles in cylindrical tubes under laminar and turbulent flow conditions, J. Aerosol Sci., 31, 335$348,2000$.

Maßling, A., Wiedensohler, A., and Voutilainen, A.: Hygroscopic properties of submicrometer aerosol particles during ACE-Asia, in: Abstracts of the European Aerosol Conference 2003, vol. 1, pp. S9-S10, 2003.

McFiggans, G., Alfarra, M., Allan, J., Bower, K., Coe, H., Cubison, M., Topping, D., Williams, P., Decesari, S., Facchini, C., and Fuzzi, S.: Simplification of the representation of the organic component of atmospheric particulates, Faraday Discuss., 130, 341, doi:10.1039/b419435g, 2005.

McFiggans, G., Artaxo, P., Baltensperger, U., Coe, H., Facchini, M.-C., Feingold, G., Fuzzi, S., Gysel, M., Laaksonen, A., Lohmann, U., Mentel, T., Murphy, D., O’Dowd, C., Snider,
J., and Weingartner, E.: The effect of physical and chemical aerosol properties on warm cloud droplet activation, Atmos. Chem. Phys., 6, 2593-2649, 2006,

http://www.atmos-chem-phys.net/6/2593/2006/.

McKeen, S. and Liu, S.: Hydrocarbon ratios and photochemical history of air masses, Geophys. Res. Lett., 20, 2363-2366, 1993.

McKeen, S., Liu, S., Hsie, E.-Y., Lin, X., Bradshaw, J., Smyth, S., Gregory, G., and Blake, D.: Hydrocarbon ratios during PEM West A: a model perspective, J. Geophys. Res., 101D, 20872109, 1996.

McMurry, P., Litchy, M., Huang, P.-F., Cai, X., Turpin, B., Dick, W., and Hanson, A.: Elemental composition and morphology of individual particles separated by size and hygroscopicity with the TDMA, Atmos. Environ., 30, 101-108, 1996.

McMurry, P. H. and Stolzenburg, M. R.: On the sensitivity of particle size to relative humidity for Los Angeles Aerosols, Atmos. Environ., 23, 497-507, 1989.

Molina, M. J., Ivanov, A. V., Trakhtenberg, S., and Molina, L. T.: Atmospheric evolution of organic aerosol, Geophys. Res. Lett., 31, L22104, doi:10.1029/2004GL020910, 2004.

Moshammer, H. and Neuberger, M.: The active surface of suspended particles as a predictor of lung function and pulmonary symptoms in Austrian school children, Atmos. Environ., 37, 1737-1744, 2003.

Neuberger, M., Moshammer, H., and Kundi, M.: Declining ambient air pollution and lung function improvement in Austrian children, Atmos Environ, 36, 1733-1736, 2002.

Neuberger, M., Schimek, M., Horak Jnr, F., Moshammer, H., Kundi, M., Frischer, T., Gomiscek, B., Puxbaum, H., Hauck, H., and AUPHEP-Team.: Acute effects of particulate matter on respiratory diseases, symptoms and functions: epidemiological results of the Austrian Project on Health Effects of Particulate Matter (AUPHEP), Atmos. Environ., 38, 3971-3981, 2004.

O’Dowd, C., Facchini, M., Cavalli, F., Ceburnis, D., Mircea, M., Decesari, S., Fuzzi, S., Yoon, Y., and Putaud, J.-P.: Biogenically driven organic contribution to marine aerosol, Nature, 431, 676680, 2004.

Park, S. and Lee, K.: Condensational growth of polydisperse aerosol for the entire particle size range, Aerosol Sci. Technol., 33, 222-227, 2000.

Park, S., Lee, K., Shimada, M., and Okuyama, K.: Alternative analytical solution to condensational growth of polydisperse aerosols in the continuum regime, J. Aerosol Sci., 32, 187-197, 2001.

Parrish, D., Hahn, C., Williams, E., Norton, E., Fehsenfeld, F., Singh, H., Shetter, J., Gandrud, B., and Ridley, B.: Indications of photochemical histories of Pacific air masses from measurements of atmospheric trace species at Point Arena, California, J. Geophys. Res., 103D, 339-359, 1992.

Penttinen, P., Timonen, K., Tiittanen, P., Mirme, A., Ruuskanen, J., and Pekkanen, J.: Ultrafine particles in urban air and respiratory health among adult asthmatics, Eur. Respir. J., 17, 428-435, 2001.

Pich, J., Friedlander, S., and Laj, F.: The self-preserving particle size distribution for coagulation by Brownian motion. III. Smoluchowski coagulation and simultaneous Maxwellian condensation, J. Aerosol Sci., 1, 115-126, 1970.

Pope, C., Schwartz, J., and Ransom, M.: Daily mortality and PM10 pollution in Utah valley, Arch. Environ. Health, 47, 211-217, 
1992.

Pope III, C.: Review: epidemiological basis for particulate air pollution health standards, Aerosol Sci. Tech., 32, 4-14, 2000.

Putaud, J.-P., Raes, F., Van-Dingenen, R., Brüggemann, E., Facchini, M.-C., Decesari, S., Fuzzi, S., Gehrig, R., Hüglin, C., Laj, P., Lorbeer, G., Maenhaut, W., Mihalopoulos, N., Müller, K., Querol, X., Rodriguez, S., Schneider, J., Spindler, G., ten Brink, H., Torseth, K., and Wiedensohler, A.: A European aerosol phenomenology. 2: chemical characteristics of particulate matter at kerbside, urban, rural and background sites in Europe, Atmos. Environ., 38, 2579-2595, 2004.

Rader, D. and McMurry, P.: Application of the tandem differential mobility analyser for studies of droplet growth or evaporation, J. Aerosol. Sci., 17, 771-787, 1986.

Raymond, T. M. and Pandis, S. N.: Formation of cloud droplets by multicomponent organic particles, J. Geophys. Res., 108(D15), 4469, doi:10.1029/2003JD003503, 2003.

Reddy, M. S. and Boucher, O.: A study of the global cycle of carbonaceous aerosols in the LMDZT general circulation model, J. Geophys. Res., 109(D14), 202, doi:10.1029/2003JD004048, 2004.

Riemer, N., Vogel, H., and Vogel, B.: Soot aging time scales in polluted regions during day and night, Atmos. Chem. Phys., 4, 1885-1893, 2004,

http://www.atmos-chem-phys.net/4/1885/2004/.

Roberts, J., Fehsenfeld, F., Liu, S., Bollinger, M., Hahn, C., Albritton, D., and Sievers, R.: Measurements of aromatic hydrocarbon ratios and NOx concentrations in the rural troposphere: observation of air mass photochemical aging and $\mathrm{NO}_{\mathrm{x}}$ removal, Atmos. Environ., 18, 2421-2432, 1984.

Rudolph, J. and Czuba, E.: On the use of isotopic composition measurements of volatile organic compounds to determine the photochemical age of an air mass, Geophys. Res. Lett., 27, 3865-3868, 2000.

Rudolph, J. and Johnen, F.: Measurments of light hydrocarbons over the Atlantic in regions of low biological activity, J. Geophys. Res., 95D, 583-591, 1990.

Schwartz, J., Dockery, D., and Neas, L.: Is daily mortality associated with fine particles?, J. Air Waste Manage., 46, 927-939, 1996.

Svenningsson, I. B., Hansson, H. C., Wiedensohler, A., Ogren, J. A., Noone, K. J., and Hallberg, A.: Hygroscopic growth of aerosol particles in the Po Valley, Tellus, 44B, 556-569, 1992.

Svenningsson, I. B., Hansson, H. C., Wiedensohler, A., Ogren, J. A., Noone, K. J., Hallberg, A., and Colvile, R.: Hygroscopic growth of aerosol particles and its influence on nucleation scavenging in Cloud - experimental results from Kleiner-Feldberg, J. Atmos. Chem., 19(1-2), 129-152, 1994.

Swietlicki, E., Zhou, J., Berg, O., Nilsson, E., Aalto, P., and Leck, C.: Hygroscopic behaviour of aerosol particles in the Arctic marine boundary layer - Relation to air mass history and mixing, J. Aerosol Sci., 29(S1), S9-S10, 1998.

Swietlicki, E., Zhou, J., Berg, O., Martinsson, B., Frank, G., Cederfelt, S., Dusek, U., Berner, A., Birmili, W., Wiedensohler, A., Yuskiewicz, B., and Bower, K.: A closure study of submicrometer aerosol particle hygroscopic behaviour, Atmos. Res., 50, 205-240, 1999.

Swietlicki, E., Zhou, J., Covert, D., Hämeri, K., Busch, B., Väkevä, M., Dusek, U., Berg, O., Wiedensohler, A., Aalto, P., Mäkelä,
J., Martinsson, B., Papaspiropoulos, G., Mentes, B., Frank, G., and Stratmann, F.: Hygroscopic properties of aerosol particles in the north-eastern Atlantic during ACE-2, Tellus, 52B, 201-227, 2000.

Sydbom, A., Blomberg, A., Parnia, S., Stenfors, N., Sandstrom, T., and Dahlen, S. E.: Health effects of diesel exhaust emissions, Eur. Resp. J., 17, 773-746, 2001.

Topping, D., McFiggans, G., and Coe, H.: A curved multicomponent aerosol hygroscopicity model framework: Part - Inorganic compounds, Atmos. Chem. Phys., 5, 1205-1222, 2005a.

Topping, D., Coe, H., McFiggans, G., Burgess, R., Allan, J., Alfarra, M., Bower, K., Choularton, T., Decesari, S., and Facchini, M.-C.: A curved multi-component aerosol hygroscopicity model framework: Part 2 - Including organic compounds, Atmos. Chem. Phys., 5, 1223-1242, 2005b.

Trakumas, S., Juozaitis, A., Buzorius, G., Girgždys, A., and Ulevièius, V.: Investigations of hygroscopical properties of atmospheric aerosol particles, J. Aerosol Sci., 26, S371-S372, 1995.

Väkevä, M., Kulmala, M., Stratmann, F., and Hämeri, K.: Field measurements of hygroscopic properties and state of mixing of nucleation mode particles, Atmos. Chem. Phys., 2, 55-66, 2002, http://www.atmos-chem-phys.net/2/55/2002/.

van Dingenen, R., Raes, F., Putaud, J.-P., Baltensperger, U., Charron, A., Facchini, M.-C., Decesari, S., Fuzzi, S., Gehrig, R., Hansson, H.-C., Harrison, R., Hüglin, C., Jones, A., Laj, P., Lorbeer, G., Maenhaut, W., Palmgren, F., Querol, X., Rodriguez, S., Schneider, J., tenBrink, H., Tunved, P., Torseth, K., Wehner, B., Weingartner, E., Wiedensohler, A., and Wahlin, P.: A European aerosol phenomenology. 1: Physical characteristics of particulate matter at kerbside, urban, rural and background sites in Europe, Atmos. Environ., 38, 2561-2577, 2004.

Volkamer, R., Jimenez, J. L., San Martini, F., Dzepina, K., Zhang, Q., Salcedo, D., Molina, L. T., Worsnop, D. R., and Molina, M. J.: Secondary Organic Aerosol Formation from Anthropogenic Air Pollution: Rapid and Higher than Expected, Geophys. Res. Lett., 33(17), L17811, doi:10.1029/2006GL026899, 2006.

Weingartner, E., Baltensperger, U., and Burtscher, H.: Growth and structural change of combustion aerosols at high relative humidity, Environ. Sci. Technol., 29, 2982-2986, 1995.

Weingartner, E., Burtscher, H., and Baltensperger, U.: Hygroscopic properties of carbon and diesel soot particles, Atmos. Environ. 31, 2311-2327, 1997.

Williams, M.: Growth rates of liquid drops for large saturation ratios, J. Aerosol Sci., 26, 477-487, 1995.

Williams, P., Gallagher, M., Choularton, T., Coe, H., Bower, K., and McFiggans, G.: Aerosol development and interaction in an urban plume, Aerosol Sci. and Technol., 32, 120-126, 2000.

Wilson, R. and Spengler, J.: Particles in our air, Harvard Univeristy Press, USA, 1996.

Zhang, Q., Alfarra, M., Worsnop, D., Allan, J., Coe, H., Canagaratna, M., and Jimenez, J.: Deconvolution and Quantification of Hydrocarbon-Like and Oxygenated Organic Aerosols Based on Aerosol Mass Spectrometry, Environ. Sci. Technol., 39, 4938-4952, 2005a.

Zhang, Q., Canagaratna, M. R., Jayne, J. T., Worsnop, D. R., and Jimenez, J.-L.: Time- and size-resolved chemical composition of submicron particles in Pittsburgh: Implications for aerosol sources and processes, J. Geophys. Res., 110, D07S09, 
doi:10.1029/2004JD004649, 2005b.

Zhang, Q., Worsnop, D. R., Canagaratna, M. R., and Jimenez, J. L.: Hydrocarbon-like and Oxygenated Organic Aerosols in Pittsburgh: Insights into Sources and Processes of Organic Aerosols, Atmos. Chem. Phys., 5, 3289-3311, 2005c.

Zhang, X., McMurry, P., Hering, S., and Casuccio, G.: Mixing characteristics and water content of submicron aerosols measured in Los Angeles and at the Grand Canyon, Atmos. Environ., 27A, 1593-1607, 1993.
Zhou, J., Swietlicki, E., Hansson, H. C., and Artaxo, P.: Submicrometer aerosol particle size distribution and hygroscopic growth measured in the Amazon rain forest during the wet season, J. Geophys. Res., 107(D20), 8055, doi:10.1029/2000JD000203, 2002.

Zimmer, A.: The influence of metallurgy on the formation of welding aerosols, J. Environ. Monitor., 4, 628-632, 2002. 